\title{
Enza Colicchi (éd.), Per una pedagogia critica. Dimensioni teoriche e prospettive pratiche
}

Rome, Carocci Editore, 2009, 190 p.

\section{Michel Ostenc}

\section{(2) OpenEdition}

\section{Journals}

Édition électronique

URL : http://journals.openedition.org/assr/22890

DOI : $10.4000 /$ assr.22890

ISSN : $1777-5825$

Éditeur

Éditions de l'EHESS

Édition imprimée

Date de publication : 31 décembre 2011

Pagination : 148

ISBN : 9782713223273

ISSN : 0335-5985

Référence électronique

Michel Ostenc, «Enza Colicchi (éd.), Per una pedagogia critica. Dimensioni teoriche e prospettive pratiche », Archives de sciences sociales des religions [En ligne], 156 | octobre-décembre 2011, document 156-36, mis en ligne le 14 février 2012, consulté le 21 septembre 2020. URL : http:// journals.openedition.org/assr/22890; DOI : https://doi.org/10.4000/assr.22890

Ce document a été généré automatiquement le 21 septembre 2020.

(c) Archives de sciences sociales des religions 


\section{Enza Colicchi (éd.), Per una pedagogia critica. Dimensioni teoriche e prospettive pratiche}

Rome, Carocci Editore, 2009, 190 p.

\section{Michel Ostenc}

\section{RÉFÉRENCE}

Enza Colicchi (éd.), Per una pedagogia critica. Dimensioni teoriche e prospettive pratiche, Rome, Carocci Editore, 2009, 190 p.

1 La modernité apparaît souvent aujourd'hui comme un projet inachevé, et les échos d'un certain classicisme veulent que nous soyons définitivement sortis de la prétention d'englober le monde dans une pensée rationnelle. Le temps devient le centre de la pensée et l'être est appréhendé en situation, non pas dans le ciel de ses idées. Une caractéristique de la modernité est l'éclatement de la société en fragments dont l'autonomie engendre des névroses souvent amplifiées par un individualisme narcissique. Elle se retourne contre son projet initial en produisant des individus sans avenir et des gouvernants moins actifs que réactifs. L'intention de l'ouvrage dirigé par Enza Colicchi est de la réhabiliter par une attitude critique capable d'interpeller la vérité dans ses effets de pouvoir et le pouvoir dans ses discours de vérité.

2 L'ambition d'une critique conçue comme recherche de la vérité est de favoriser une prise de conscience de la nature des éléments constitutifs de la personne. Elle permet d'affranchir l'individu des principes à valeur universelle et des rigidités méthodologiques. Un projet éducatif est la synthèse de plusieurs intentions et les auteurs de l'ouvrage s'interrogent sur les critères constitutifs d'une pédagogie critique. Enza Colicchi élabore à cet effet une théorie résolument tournée vers la pratique de l'action éducative. Elle constate que le rationalisme des théories de l'éducation découle généralement de valeurs idéales et de doctrines philosophiques, politiques ou 
religieuses. Leur difficulté à générer des actions concrètes vient de l'absence d'un procédé capable de traduire leurs abstractions en réalités éducatives et il s'agit de combler cette lacune en séparant la théorie pédagogique des pratiques d'éducation. L'école dispense trop souvent des enseignements fondés sur des modèles universels abstraits qui conduisent à des savoirs réductifs. Une pédagogie critique doit l'aider à inventer d'autres formes de pensée capables d'explorer des domaines inaccessibles aux modèles traditionnels. Dans cette démarche d'une rationalité pratique, la finalité de l'éducation doit jouer un rôle de filtre et de grille pour traduire des données scientifiques en langage pédagogique.

3 Un problème fondamental reste celui de la singularité du sujet et de son appartenance à un éthos commun qu'une pédagogie critique doit aborder sous l'angle de l'émancipation de la conscience individuelle. La différence peut naître d'un effort de responsabilité du sujet remettant en cause les éléments fondateurs de son identité, ce qui est un défi lancé à un monde moderne dominé par l'indifférence et le narcissisme. La théorie ébauchée par Enza Colicchi peut donner naissance à une formation du citoyen cultivant les facultés d'autodétermination du sujet. L'organisation hiérarchisée de l'école traditionnelle et le caractère théorique de ses manuels seraient des obstacles à une éducation démocratique; mais des écoles nouvelles pourraient y parvenir en enrichissant les connaissances par la recherche individuelle et les comportements sociaux par des solutions concrètes.

4 La modernité obéit sans doute à une rationalisation économique, à un individualisme toujours plus poussé, à la compréhension mutuelle ou au manque de reconnaissance des individus ; mais l'école de Francfort a montré qu'une pensée critique pouvait aussi reposer sur des pathologies de l'expérience temporelle. On est certes séduit par l'humanisme d'une pensée qui envisage l'éducation comme un développement des capacités du sujet chaque fois que son autonomie est en jeu ; mais cette interprétation condamne l'utilisation de la critique en pédagogie au service des potentialités cognitives, comme si le développement de l'intelligence s'opposait à la formation de la personne. Le rationalisme apporte des réponses qui séduisent l'intelligence mais laissent l'âme insatisfaite. Il donne au problème de la destinée une réponse qui n'éclaire pas le sens de la vie. Le renouveau de l'éducation ne saurait s'en contenter. La dimension humaine de la réflexion pédagogique passe sans doute par la rigueur intellectuelle, mais elle ne saurait négliger une dimension morale. La vie se joue au niveau de la conscience. La thèse de l'auteur pose par contre le problème fondamental des finalités de l'éducation qu'elle place au cœur de sa pédagogie critique. Elle souligne la nécessité d'une nouvelle définition de l'enseignement en fonction de ce que la société en attend et elle pose implicitement la question du rôle de l'école dans la formation humaniste ou professionnelle du sujet. L'éducation démocratique pose par contre l'éternel problème d'une école idéale servant de modèle de société ou d'une école au service de la société. Ces réserves mises à part, la pédagogie critique d'Enza Colicchi ouvre de stimulantes perspectives dont on attend les développements avec beaucoup d'intérêt. 